\title{
Commentary: The Idea on Motion (Actual Motion) In 3-Dimensional Visual Art
}

\author{
Hilal Mazlan ${ }^{1}$ \\ ${ }^{1}$ Department of Fine Art, Faculty of Art and Design, Universiti Teknologi MARA, \\ Perak Branch, Seri Iskandar Campus, 32610 Seri Iskandar, Perak, MALAYSIA. \\ Email: ${ }^{1}$ hilal@uitm.edu.my
}

Published: 28 September 2019

eISSN: 2550-214X (C) 2019. The Authors. Published for Idealogy Journal of Arts and Social Science by UiTM Press. This is an Open Access article distributed under the terms of the Creative Commons Attribution-NonCommercial-NoDerivatives License (http://creativecommons.org/licenses/by-nc-nd/4.0/), which permits non-commercial re-use, distribution, and reproduction in any medium, provided the original work is properly cited, and is not altered, transformed, or built upon in any way.

\section{"Why must art be static??” (Alexander Calder)}

Many people thought that motion in art began when Alexander Calder introduce his colourful, whimsical abstract public sculptures, among his sculptures are Red Mobile (1956) and Trepeid (1972).

Actually, actual motion or movement in art has begun in 1919 when Naum Gabo introduces his work Kinetic Construction Standing Wave. Kinetic Construction (Standing Wave) was initially created by Naum Gabo to demonstrate kinetic energy to a class. Here a metal strip stand is mechanized to create a motion that produces the illusion of volume.

In the early 20th century, artists became fascinated by speed and machinery. One technique they used was to show a single moving figure with many superimposed positions. Marcel Duchamp's Nude Descending a staircase (1912) was directly influenced by the photographs of Etienne-Jules Marey A Sword Thrust (1895). In the Futurist era (1909- late 1920s), motion or movement has been a great influence due to the industrial revolution. Artist frequently display motion in their artwork by showing multiple image or blurry motion.

In his work Kinetic Construction (Standing Wave), Naum Gabo at first was trying to demonstrate to his student about constructivist ideas. It took Gabo nearly 3 years to complete this concept. This work elaborates so much about volume, time and space. He (Gabo) always talks about the important of controlling space in sculpture.

"It was done in a primitive way, but the only way I could have done it at that time, when conditions were such that looking for elaborate mechanisms was to search for a golden plate from the moon!" (Naum Gabo, 1969)

Talking about motion in art, another artist that should been mention is Swiss artist Jean Tinguely. When looking through the artwork of his, we can almost see the craziness in his creation. The composition of the machine and sometimes found object. Tinguely's work is a protest against the white space, the museum and sterility. He wants to create ugliness; he wants to create a machine on a machine. All of his machines were all perpetual, what he wants to see is what the audience can interpret from his work. Somehow his works usually trigger different kind of emotions he doesn't care whether it is fascination, anger or uneasiness. He just wanted to create art that move and believe that art should not be so pure. 
Nature also brings great influence in bringing motion into art. There were many artists that were inspired by this idea. Nature has always been an inspiration in man-made creation. That is even a term that was developed for design that comes from nature, it is called Biomimicry. Examining the design of nature has aided in the development of almost every aspect of our lives, and most of us often without realizing the benefit from these inspired revelations several times a day. Among the artist that shares this idea are Bob Potts through his Synchronous Cycle (2013) and Theo Jansen through his work The Strandbeast series (since 1990).

"My work is the manifestation of ideas that come to me from the natural world. The grace and form of all living things, and the way they interact, leaves me in awe." (Bob Potts)

The motion and movement that were projected through Bob Potts sculpture are always derived from the motion from animal. For example, Synchronous Cycle showing a motion of a group of fish swimming in the water and his G-Plane was obviously showing how he imitates motion and movement from a flying bird. Comparing to Theo Jansen's work The Strandbeast series, although the aesthetic and visual is world apart, we can see the sentiment that these two artists share.

Theo Jansen, through his Strandbeast said that his work was his idea of creating his own life-form. The physical aspect of his work is so bizarre and usually constructed using nothing only than electrical tube and simple jointing method, but the movement that come when this 'creature' walks and move was so lifelike. It looks like some sort of a giant insect straying on the earth surface.

As a far as actual motion in 3 dimensional arts is concern, it can be concluded that among the strong aspects that bring actual motion into 3 dimensional arts are:

1. The thought that modern art should expand to another aspect (art should not be static).

2. The connection between man and machine and how it affected us.

3. Biomimicry, how artist felt obliged and fascinated in bringing the element of nature through their works.

Of course, the aesthetics and style of artworks are usually originated from the artists that produce them. But the idea that the artist delivered sometimes come from their surroundings, interest, obsession or what do they valued the most. Technologies that evolve rapidly are also among the reason that makes artists felt that art should keep up. Nowadays, putting certain art into certain category is more and more difficult because the evolution and change in thoughts and perspectives that involve to the systems and people surrounding the art itself.

\section{REFERENCES}

Amsterdam, S. M. (Composer). (n.d.). Jean Tinguely, Machine Spectacles. [J. Tinguely, Performer, \& S. M. Amsterdam, Conductor]

George, H. (2014). challenging solidity. In The Element Of Sculpture (p. 142). PHAIDON.

M.A.D.Gallery . (n.d.). Retrieved 10 12, 2018, from M.A.D.Gallery Geneva: https://www.madgallery.net/geneva/en/creators/bob-potts

pipes, a. (2009). foundation art+design. london: Lauren King Publishing.

TATE. (n.d.). Retrieved 9 28, 2018, from https://www.tate.org.uk/art/artworks/gabo-kineticconstruction-standing-wave-t00827 